\title{
QUALITY OF LIFE AND DEPRESSION AMONG FEMALE PATIENTS UNDERGOING SURGICAL TREATMENT FOR BREAST CANCER: A PROSPECTIVE STUDY
}

\author{
Anto Dujmovicí ${ }^{1,2}$, Darko Marčinko ${ }^{1,3}$, Krešimir Bulićín $^{1,2}$, Hrvoje Kisić ${ }^{2}$, \\ Mladen Duduković ${ }^{2}$ \& Davor Mijatović ${ }^{1,2}$ \\ ${ }^{1}$ School of Medicine, University of Zagreb, Zagreb, Croatia \\ ${ }^{2}$ Department of Plastic, Reconstructive and Cosmetic Surgery, University Hospital Center Zagreb, Zagreb, Croatia \\ ${ }^{3}$ Department of Psychiatry, University Hospital Center Zagreb, Zagreb, Croatia
}

received: 15.2.2017;

revised: 23.5.2017;

accepted: 5.6.2017

\section{SUMMARY}

Background: Breast carcinoma is the most common malignant disease in women in the majority of developed countries. The development of depression as well as the quality of life $(Q o L)$ in these patients depends not only on the result of oncologic treatment, but on the cosmetic outcome as well. The primary aim of this prospective study was to investigate the changes in QoL and depressive symptoms among patients undergoing surgical treatment for breast cancer.

Subjects and methods: We conducted a prospective study that included 100 female patients (mean age 60.26 years) who underwent surgical and oncological treatment for breast carcinoma at the University Hospital Center Zagreb, Croatia. The patients were photographed before and after treatment and were required to fill out a standardized quality of life questionairres QLQ - C30 and $Q L Q-B R 23$, Beck Depression Inventory (BDI) and a questionnaire on breast asymmetry.

Results: Our results show that patients had significantly higher QoL levels compared with their pre-surgical results. Statistical trend of a lower degree of depression was also observed. A worse cosmetic outcome (i.e., postoperative assymetry) was associated with a lower QoL, but there was no association with depression. Depression was significantly related to the level of pain and lower financial status.

Conclusion: QoL improved after surgical treatment of breast cancer and was dependant on postoperative asymmetry, whereas the findings for depressive symptoms remained less clear. Future research should investigate more factors that may contribute to the QoL and degree of depression in this patient population.

Key words: breast surgery - breast cancer - breast asymmetry - depression - quality of life

\section{INTRODUCTION}

Breast cancer is the most common malignancy in females in Croatia and in most of the western countries as well (Ferlay et al. 2012). During 2013, there were 2557 new cases of breast cancer reported in Croatia (Registar za rak Republike Hrvatske 2013). The treatment for breast cancer consists of surgery and adjuvant therapy. Due to cancer prevention measures such as regular examinations by the general practitioner and mammography screenings, this disease is usually diagnosed in the early stages and requires only a lumpectomy in the majority of cases (Veronesi et al. 1990). This surgical technique preserves the breast contour and avoids the need for more radical procedures such as radical mastectomy. Following a lumpectomy, postoperative radiation treatment is always applied (Fisger et al. 2002). Since Veronesi began with breast conserving surgery in patients with diagnosed breast cancer, numerous studies have confirmed the equal oncological value of this type of surgery compared with a classic mastectomy (Veronesi \& Zurrida 2007). Although this type of surgery is minimally destructive, our experience as well as experience of other authors has shown that the cosmetic result is not always satisfactory (Stanton et al. 2001, Medina - Franco et al. 2013) Due to this, many authors have researched the influence of the cosmetic result after breast conserving therapy and observed important factors such as postoperative complications, tumor location and volume of excised tissue (tumor removal) versus breast volume (Cardoso et al. 2007). Jennifer F Waljee found that factors that contribute to breast asymmetry after sugery include younger patient age, increased BMI, larger tumor size and tumor location (upper medial and upper lateral quadrants). They also found that breast asymmetry or overall cosmetic results are dependant on the need for re-excisional surgery, postoperative seroma formation and radiotherapy (Waljee et al. 2008). Cochrane showed in his research that the maximal percentage of breast volume that can be removed without changes in the final cosmetic result is $10 \%$ (Cohrane at al. 2003). Surgery and radiotherapy influence the shape and form of the patient's breast, the quality of the skin and subcutaneous tissue and the appearance of the scar (D'Aniello et al. 1999).

In the last two decades, many research papers compared the cosmetic result, quality of life and psychosocial changes related to the type of surgical treatment conducted (Curran et al. 1998, Sheppard \& Ely 2008, 
Nano et al. 2005, Waljee et al. 2008a, Walje et al 2008b). That studies have shown that a poorer cosmetic result generally leads to a lower quality of life and higher levels of depression. In that studies authors just observed the result after the oncologic treatment. There were no investigation that would show the difference before and after surgery and oncologic tretment.

In this prospective study, we specifically focused on the relationship between quality of life and the occurrence of depression in relation to the cosmetic result by using the asymmetry test. The goals of this study were to determine the cosmetic result of breast lumpectomies following surgical and oncologic treatment and to evaluate the level of depression and the quality of life in patients before and after breast cancer treatment. Also we planned to discover if there is relationship between quality of life level, degree of depression and level of asymmetry following treatment.

\section{SUBJECTS AND METHODS}

\section{Subjects}

This study included 100 female patients who were surgically and oncologically treated at the University Hospital Centre Zagreb, Croatia. Surgical treatment included only a primary breast lumpectomy (the patients had no previous or additional surgical therapy). The study excluded patients with a history of psychiatric illness or those using psychotropic medications. Also, patients who refused adjuvant oncological treatment, patients who underwent other forms of treatment in other medical centers and patients who refused to participate in the study were not included This research was approved by the Ethics Committee at the University Hospital and School of Medicine, University of Zagreb, Croatia. A consent form was given and signed by all patients who participated in the study.

The average age of the sample group was 60.26 years. The youngest patient was 29 and the oldest 69 years. Most patients were retired (59\%), a third of them employed, and the rest were unemployed. Seventy-one percent $(71 \%)$ of women were married or in a relationship, $12 \%$ divorced, $16 \%$ widowed, and 1 patient had never married.

\section{Methods}

The questionnaires used included the quality of life QLQ - C30, QLQ - BR23, Beck Depression Inventory (BDI) and asymmetry questionnaire taken from BCTOS andmodified by Waljee and associates (Waljee and al. 2008a). Patients were asked to complete these questionnaires preoperatively and after completing oncologic treatment.

Their quality of life was assessed by patient responses to 2 generic cancer questionnaires: European Organization for Research and Treatment of Cancer Quality of Life Questionnaire version 3 (EORT QLQ-C30) and the Breast Cancer-Specific Quality of Life Questionnaire (QLQ BR-23)(Aaronson et al. 1993, Sprangers et al. 1996, Fayers et al. 2001). The QLQ-C30 contains 30 questions and has been grouped into three scales: one global QOL scale (2 questions), five function scales (15 questions) and nine symptom scales (13 questions). Scale scores are the average of responses and can be transformed linearly in a range from 0-100 (as described in the User's Guide)(dr Haes et al1999) or can be used as raw results. The QLQ-BR23 is comprised of 23 questions and has been grouped into two scales: four function scales (13 questions) and four symptom scales (8 questions). Scale scores can be transformed linearly in a range from $0-100$ or used as raw results. For both quality of life questionnaires (QLQ-C30 and QLQBR23) function scales and the global QOL scale, a higher score corresponds to a better QOL. For the symptom scales, a higher score indicates more frequent and/or intense symptom experience and thus a lower QOL (King 1996).

The Beck Depression Inventory (BDI) is a questionnaire that is used for the evaluation of the presence and intensity of depression (Beck et al. 1984). The scale consists of 21 symptoms and the patient has to choose the one that best describes their state in the indicated time period. The following criteria is used for measuring the intensity of depression: $0-4$ no depression; 57 mild depression; 8-15 moderate depression; over 16 points severe depression.

BDI has been successfully used in a number of clinical studies of depression in the general population and in studies of depression in chronic somatic patients (Beck et al. 1997, Steer et al. 1999, Tyrala et al. 2015, Uglešić et al. 2015).

Cosmetic outcome after surgery was assessed by the patient's response to eight questions from the Breast Cancer Treatment and Outcomes Survey (Stanton at al 2001). Patients were also asked to rate the differences in breast skin color using the same scale modification made by Waljee et al (Waljee et al. 2008). Answers to each question were rated on a 4 point scale (1- no difference between breasts, 2 - slight difference between breasts, 3 - moderate difference between breasts, and 4 large difference between breasts). The responses were normally distributed and averaged to generate an overall asymmetry score. For ease of reporting, response scores were categorized into three groups: minimal asymmetry (scores $<15$ ), moderate asymmetry (scores of 15 to 20), and pronounced asymmetry scores $>20$ ) (Deutsch \& Flickinger 2003, Taylor et al. 1995, Fedoric et al. 2006, Cardoso et al. 2007). Due to sample size issues, we merged the moderate and pronounced asymmetry categories for the purposes of statistical analyses.

\section{Statistical Analysis}

Statistical analysis was performed using the SPSS software package, version 20 for Windows operating system. The following parameters of descriptive sta- 
tistics were calculated: frequency, proportions, percentages, average values and the corresponding standard deviations. The reliability of the instruments is calculated using the coefficient of internal consistency (Cronbach alpha coefficient). The normality of distribution of the results obtained was verified using the Kolmogorov-Smirnov test. Nonparametric statistics used includedWilcoxon matched pairs test.Parametric analysis of the results included a t-test for dependent and independent samples. The initial level of significance was determined to be an error probability of less than $5 \%(p<0.05)$. We used the Bonferroni's adjustment for the $\mathrm{p}$ value when comparing multiple QoL dimensions before and after surgery.

\section{RESULTS}

Features of the tumor: $98 \%$ of patients had an invasive carcinoma while $2 \%$ had ductal carcinoma in situ. In 53 women, the tumor was located in the right breast, and in the other 47 women in the left. In all patients the appropriate adjuvant chemotherapy was given. The average tumor size was $18.67 \mathrm{~mm}$. The smallest tumor was $5 \mathrm{~mm}$ and the largest was $48 \mathrm{~mm}$. $55 \%$ of patients had a tumor in the outer upper quadrant, $17 \%$ in the outer lower quadrant, $14 \%$ in the lower inner quadrant, $13 \%$ in the inner upper quadrant and $1 \%$ in the central quadrant.

The average score on the asymmetry questionnaire was $13.24(\mathrm{SD}=3.726)$, but the most frequent score was 9 (distribution is positively skewed), which means that the majority of women see their breast as minimally asymmetric. More specifically, seventy-six percent (76\%) of women reported minimal asymmetry, 19\% reported moderate asymmetry, and 5\% reported significant breast asymmetry.

The average score on the Beck Depression Inventory before surgery was $10.122(\mathrm{SD}=7.248)$ - moderate depression, but after the operation it was 8.61 $(\mathrm{SD}=4.930)$ - minimal depression. The difference in the depression before and after surgery was not statistically significant (Wilcoxon matched pairs test: $\mathrm{z}=1.887$; $\mathrm{p}=0.059$ ), but the border significance level analysis suggests a statistical trend in terms of lower levels of depression after surgery.

The overall quality of life before surgery was 4.46 and after the end of treatment was 5.01. After surgery, the patient's quality of life was better than before surgery. The difference in the result before and after surgery was statistically significant (paired-samples ttest: $\mathrm{t}=3.491, \mathrm{df}=99, \mathrm{p}=0.001$ ). Detailed description of the quality of life factors and results can be found in Tables 1 and 2 .

As seen in Tables 1 and 2, the following QoL dimensions improved after breast surgery: global QoL, physical, role, cognitive and sexual functioning. On the other hand, levels of fatigue, pain, dyspnoea, and arm symptoms increased. Also patients found that future perspective worse after surgery and oncologic treatment.
We did not find a statistically significant association between the cosmetic result of conservative breast cancer treatment (i.e., minimal and moderate/significant asymmetry categories) with results on the Beck Depression Inventory (independent samples t-test: $\mathrm{t}=1.450, \mathrm{df}=98, \mathrm{p}=0.150$ ).

$24 \%$ of the patients who reported moderate or significant breast asymmetry had worse result on global health status in QLQ-C30 questionnaire comparing the rest of patients (Speramann rho=-0.235, $\mathrm{p}=0.019$ ).

$29 \%$ of patients after completing their treatment often or almost always felt pain. These patients exhibit a higher level of depression (independent samples t-test : $\mathrm{t}=3.885, \mathrm{df}=98, \mathrm{p}=0.000)$.

$16 \%$ of patients who had financial problems were found to be more depressive than those without, and this was found to be statistically significant $(\mathrm{t}=20.096$, $\mathrm{df}=98, \mathrm{p}=0.039$ ).

Study showed that grup of patients with moderate and significant asymmetry compared to patient with minimal asymmetry have better role functioning $(\mathrm{U}=1177,500 ; \mathrm{p}=0.024)$ and betetr cognitive functioning $(\mathrm{U}=1172,000 ; \mathrm{p}=0.029)$.Also sexual functionig is better in a group with moderate and significant asimmetry $(\mathrm{U}=1156,500 ; \mathrm{p}=0.038$ )

\section{DISCUSSION}

In this research, we focused on the cosmetic surgical outcome and the patients' quality of life and level of depression before and after breast surgery, as well as on the relationship between breast asymmetry and the quality of life and level of depression.

$76 \%$ of the patients reported the presence of minor asymmetry following breast surgery, 19\% reported moderate asymmetry while 5\% reported a high degree of asymmetry. These results support the findings made by Medina-Franco et al. (2013). The patients in their study reported some degree of assymmetry in $27 \%$ of patients who underwent breast surgery. One factor which correlated with a higher degree of reported asymmetry was the patient's level of education. Patients with higher degrees of education reported higher levels of breast asymmetry that suggests that this population is more self critical or posseses a higher expectation standard (Medina-Feanco et al. 2013). In our study, we did not find a correlation between asymmetry score and level of education.

Similar results were described by Taylor et al. who found that in $82 \%$ of cases, patients were satisfied with postoperative breast conserving surgery results (Taylor et al. 1995).

The patients were moderatly depressed before surgery while after surgery they improved and reported minimal depressive symptoms. Although statistically significant at a trend level, this can be described by the fact that the survey was initially filled out by the patients soon after they were diagnosed with breast cancer. 
Table 1. Differences in multiple quality of life dimensions (QLQ C30) before and after breast surgery

\begin{tabular}{|c|c|c|c|c|}
\hline QoL dimensions & Before Surgery & After Surgery & t-test & $\mathrm{p}$ \\
\hline Global health status & 4.4600 & 5.0100 & 3.491 & 0.001 \\
\hline Physical functioning & 1.4280 & 1.7140 & 5.835 & 0.000 \\
\hline Role functioning & 1.3200 & 1.5400 & 3.591 & 0.001 \\
\hline Emotional functioning & 1.9575 & 1.7400 & 2.843 & 0.005 \\
\hline Cognitive functioning & 1.4200 & 1.6300 & 3.045 & 0.003 \\
\hline Social functioning & 1.3150 & 1.4400 & 2.082 & 0.040 \\
\hline Fatigue & 1.8100 & 2.0967 & 3.989 & 0.000 \\
\hline Nausea and vomiting & 1.1550 & 1.1600 & 0.159 & 0.874 \\
\hline Pain & 1.5050 & 1.8600 & 5.064 & 0.000 \\
\hline Dyspnoea & 1.6700 & 1.9600 & 3.214 & 0.002 \\
\hline Insomnia & 1.8800 & 2.0600 & 2.018 & 0.046 \\
\hline Appetite loss & 1.4900 & 1.5500 & 0.726 & 0.470 \\
\hline Constipation & 1.3200 & 1.4100 & 1.264 & 0.209 \\
\hline Diarrhoea & 1.2300 & 1.1500 & 1.378 & 0.171 \\
\hline Financial difficulties & 1.3900 & 1.6200 & 2.416 & 0.018 \\
\hline
\end{tabular}

Bonferroni's adjustment for multiple comparisons reduced the significance level to $p=0.003$. Statistically significant values are highlighted in italics

Table 2. Differences in multiple quality of life dimensions (QLQ - BR23) before and after breast surgery

\begin{tabular}{lcccc}
\hline & Before Surgery & After Surgery & t-test & Significance $(\mathrm{p})$ \\
\hline Body image & 1.4000 & 1.5350 & 1.969 & 0.052 \\
Sexual functioning & 1.5800 & 1.8250 & 3.707 & 0.000 \\
Sexual enjoyment & 1.1200 & 1.3600 & 1.886 & 0.062 \\
Future perspective & 2.6300 & 2.2600 & 3.489 & 0.001 \\
Systematic therapy side effects & 1.5900 & 1.5171 & 1.623 & 0.108 \\
Breast symptoms & 1.3325 & 1.4275 & 2.076 & 0.040 \\
Arm symptoms & 1.4967 & 1.7933 & 4.804 & 0.000 \\
Upset by hair loss & 0.4500 & 0.4200 & 0.283 & 0.777 \\
\hline
\end{tabular}

Bonferroni's adjustment for multiple comparisons reduced the significance level to $\mathrm{p}=0.006$. Statistically significant values are highlighted in italics

The difference in depression levels between the patients with minimal and those with moderate of severe breast asymmetry was found to be statistically insignificant. Maybe the explanation to this fact lies in QLQ C30 questionnaire whose results concidering body image shows no statistical difference in body image before and after operation. Unlike our research, Waljee (Waljee et al. 2008a,b) found that worse asymmetric results correlated with higher rates of depression.

In our study, there was a positive correlation between depression and postoperative pain, as well as with financial problems following the operation. Perhaps, the former is the reason for the lack of correlation between depression and asymmetry/cosmetic result; patients could be more focused on pain and existential issues rather than personal appearance. Waljee et. al in their study did not comment on these parameters (Waljee et al. 2008a,b).

In Croatia, patients are granted full sick-leave (absence from work), during their complete surgical and oncological treatment. This sometimes requires 6-12 months and during this period, their monthly income is lower than if they were working. This could maybe be the reason thatintroduces existential obstacles, lowers the patients' quality of life and could lead to the development of depression.

Caffo reported symptoms of postoperative pain in $33 \%$ of patients which correlated with a lower quality of life score in this population (Cafoo et al. 2003). As well as the trend for a lower quality of life in patients with a higher degree of postoperative pain, we also found an increase in depressive symptoms in this population as well. Other studies showed that significantnumber of patients with chronic pain also develops achronic pain syndrome, which is manifested in intensepain, suffering, pronounced changes in behavior, decreased activity, sleep disorder, anxiety, depression,suicidal ideas, social withdrawal, irritability, fatigue,cognitive difficulties, impaired sexual activities, hopelessness, helplessness and avoiding behavior. Numerous studies support the thesis that pain causes depression because of the current depressive episode which start after the beginning of pain (Braš et al. 2010).

This study showed that the patient's overall quality of life is correlated with the level of asymmetry. A higher asymmetry score was found to be associated with better cognitive functioning and better sexual functioning. 
Although these results at first seem illogical, we can describe this observation as a method at which patients with a worse cosmetic outcome attempt to compensate for their appearance by "keeping busy" with multiple tasks, increasing their cognitive function, and sexual desire. After operation physical, cognitive, social and role functioning is better. It is hard to explain that physical funcioning is better although patinet feel pain, arm symptoms, breast simptoms are more tired and complain on dyspnea. Maybe just the fact that they are operated and cancer is removed together with better cognitive function gives them push them to start normal functioning compared to period just before operation.

Our study was orientated to investigate an important dilema that health professionals face daily; can surgeons, oncologists and other hospital personel recognize which patients are at an increased risk of developing negative psychological symptoms after being diagnosed and operated with breast cancer.

The factors and elements observed in this study can be used postoperatively as a method of detecting and recognizing groups of patients who are at an incresead risk of developing depressive syptoms as a consequence of poor cosmetic outcome or a deteriorated quality of life. These patients could be referred to a psychologist or psychiatrist prior to developing depressive symptoms which will undoubtedly influence their treatment and overall quality of life in a postive manner.

\section{CONCLUSION}

QoL improved after surgical treatment of breast cancer and was negatively associated with postoperative asymmetry. The findings for depressive symptoms remained less clear (i.e., reduction in depression levels following surgery was significant at a trend level, while there was no association between depression and breast asymmetry). However, depression was significantly related to the level of postoperative pain and lower financial status. Future research should observe more factors that may influence and contribute to the quality of life and the degree of depression in this patient population.

\section{Acknowledgements: None.}

Conflict of interest: None to declare.

\section{Contribution of individual authors:}

Anto Dujmović: design of the study, literature searches and analyses, statistical analyses, interpretation of data;

Darko Marčinko: design of study, interpretation of data; Krešimir Bulić: statistical analyses, literature searches; Hrvoje Kisić: data collecting, literature searches; Mladen Duduković: data collecting, literature searches; Davor Mijatović: design of study, interpretation of data.

\section{References}

1. Aaronson NK, Ahmedzai S, Bergman B, Bullinger M, Cull $A$, Duez NJ et al: The European Organization for Research and Treatment of Cancer QLQ-C30: a qualityof-life instrument for use in international clinical trials in oncology. J Natl Cancer Inst 1993; 85:365-376.

2. Beck AT \& Steer RA: Internal consistencies of the original and revised Beck Depression Inventory. J Clin Psychol 1984; 40:1365-1367.

3. Beck AT, Guth D, Steer RA \& Ball R: Screening for major depression disorders in medical inpatients with the Beck Depression Inventory for Primary Care. Behav Res Ther 1997; 35:785-91.

4. Braš M, Đorđević V, Gregurek $R \&$ Bulajić M: Neurobiological and clinical relationship between psychiatric disorders and chronic pain. Psychiatria Danubina 2010; 22:221-226.

5. Caffo O, Amichetti M, Ferro A, Lucenti A, Valduga $F \&$ Galligioni E: Breast Cancer Research and Treatment 2003; 80:39-48.

6. Cardoso MJ, Cardoso J, Santos AC, Vrieling C, Christie $D$, Liljegren $G$ et al: Factors determining esthetic outcome after breast cancer conservative treatment. Breast J 2007; 13:140-146.

7. Cochrane RA, Valasiadou P, Wilson ARR, Al-Ghazal SK \& Macmillian RD: Cosmesis and satisfaction after breastconserving surgery correlates with the percentage of breast volume excised. British Journal of Surgery 2003; 90:1505-1509.

8. Curran D, van Dongen JP, Aaronson NK, Kiebert G, Fentiman IS, Kurebayashi J, Otak K et al: Quality of life of early-stage breast cancer patients treated with radical mastectomy or breast-conserving procedures: Results of EORTC trial 10801. Eur J Cancer 1998; 34:307-314.

9. D'Aniello C, Grimaldi L, Barbato A, Bosi B \& Carli A: Cosmetic results in 242 patients treated by conservative surgery for breast cancer. Scand J Plast Reconstr Surg Hand Surg 1999; 33: 419-422.

10. Deutsch $M \&$ Flickinger JC: Patient characteristics and treatment factors affecting cosmesis following lumpectomy and breast irradiation. Am J Clin Oncol 2003; 23:350-353.

11. Fayers PM, Aaronson NK, Bjordal K, Corran $M$ \& Groenvol M: EORTC QLQ-C30 Scoring Manual, on behalf of the EORTC Quality of Life Study Group. Third edition. Brussels, Belguim: EORTC Quality of Life Study Group; 2001. pp. 1-86.

12. Fedorcik GG, Sachs R, \& Goldfarb MM: Oncologic and cosmetic results following breast-conserving therapy with $0.5 \mathrm{~cm}$ margins in 100 consecutive patients. Breast $J$ 2006; 12:208-211

13. de Haes J, Curran D, Young T, Bottomely A, Flechtner H, Aaronson $N$ et al: Guidelines for Assessing Quality of Life in EORTC Clinical Trials on behalf of the EORTC Quality of Life Study Group. Brussels, Belguim: EORTC Quality of life Study Group 1999; pp. 1-41.

14. Fisher B, Anderson S, Bryant J, Margolese RG, Deutsch M, Fisher ER et al: Twenty-year follow-up of a randomized trial comparing total mastectomy, lumpectomy, and lumpectomy plus irradiation for the treatment of invasive breast cancer. N Engl J Med 2002; 347:233-1241.

15. King MT: The interpretation of scores from the EORTC quality of life questionnaire QLQ-C30. Qual Life Res 1996; 5:555-567. 
16. Medina-Franco H, Rojas-García P, Suárez-Bobadilla YL \& Sánchez-Ramón A; Factors associated with breast symmetry after breast conserving surgery for cancer. Rev Invest Clin 2013; 65:379-83.

17. Nano MT, Gill PG, Kollias J, Bochner MA, Malycha P \& Winefield HR: Psychological impact and cosmetic outcome of surgical breast cancer strategies. ANZ J Surg 2005; 75:940-947.

18. Registar za rak Republike Hrvatske 2013:http://www.hzjz.hr/sluzbe/sluzba-zaepidemiologiju/odjel-za-nadzor-i-istrazivanje-ne-zaraznihbolesti/odsjek-za-zlocudne-bolesti-s-registrom-za-rak/

19. Sheppard LA \& Ely S: Breast cancer and sexuality. Breast J 2008; 14:176-181.

20. Sprangers MAJ, Groenvold M, Arraras JI,Franklin J, te Velde A, Muller $M$ et al: The European Organization for Research and Treatment of Cancer breast cancer-specific quality-of-life questionnaire module: first results from a three-country field study. J Clin Oncol 1996; 14:2756-2768.

21. Stanton AL, Krishnan L \& Collins CA: Form or function? Part 1: Subjective cosmetic and functional correlates of quality of life in women treated with breast-conserving surgical procedures and radiotherapy. Cancer 2001; 91:2273-2281.

22. Steer RA, Cavalieri TA, Leonard DM \& Beck AT: Use of the Beck Depression Inventory for Primary Care to screen for major depression disorders. Gen Hosp Psychiatry 1999: 21:106-11.
23. Taylor ME, Perez CA, Halverson KJ, Kuske RR, Philpott GW, Garcia DM et al: Factors influencing cosmetic results after conservation therapy for breast cancer. $C$ Int J Radiat Oncol Biol Phys 1995; 31:753-64.

24. Tyrata K, Seweryn M, Bonk M, Bulska W, Orszulak K, Bratek A, Krysta K: Evaluation of the utility of Liebowitz Social Anxiety Scale and Barratt Impulsiveness Scale in the diagnosis of social anxiety, impulsivity and depression. Psychiatr Danub 2015; 27:S223-6.

25. Uglešić B, Ljutić D, Lasić D, Jeličić I, Višić V, Glavina T, et al: Depression and serum interleukin-6 levels in patients on dialysis. Psychiatr Danub 2015; 27:168-73.

26. Veronesi U, Banfi A, Salvadori B, Luini A, Saccozzi R, Zucali $R$ et al: Breast conservation is the treatment of choice in small breast cancer: Long-term results of a randomized trial. Eur J Cancer 1990; 26:668-670.

27. Veronesi $U$ \& Zurrida S: Breast conservation: Current results and future perspectives at the European Institute of Oncology. International Journal of Cancer 2007; 120:1381-1386.

28. Waljee JF, Hu ES, Newman LA \& Alderman AK: Predictors of breast asymmetry after breast-conserving operation for breast cancer. J Am Coll Surg 2008; 206:274-80.

29. Waljee JF, Hu ES, Ubel PA, Smith DM, Newman LA \& Alderman AK: Effect of esthetic outcome after breastconserving surgery on psychosocial functioning and quality of life. J Clin Oncol 2008; 26:3331-3337.

Correspondence:

Anto Dujmović, MD

Department of Plastic, Reconstructive and Cosmetic Surgery,

University Hospital Center Zagreb

Kišpatićeva 12, 10000 Zagreb, Croatia

E-mail:dujmovic.anto@gmail.com 